\title{
Application of tungsten-copper composite heat sink materials to plasma-facing component mock-ups
}

\author{
A. v. Müller ${ }^{a, b}$, B. Böswirth ${ }^{a}$, V. Cerric ${ }^{c}, H . G^{2}$ Greuner $^{a}$, R. \\ Neu $^{\mathrm{a}, \mathrm{b}}$, U. Siefken ${ }^{\mathrm{d}}$, E. Visca ${ }^{\mathrm{c}}$, J.H. You ${ }^{\mathrm{a}}$ \\ aMax-Planck-Institut für Plasmaphysik, 85748 Garching, Germany \\ ${ }^{b}$ Technische Universität München, 85748 Garching, Germany \\ ${ }^{\mathrm{C}}$ ENEA, 00044 Frascati RM, Italy \\ ${ }^{\mathrm{d}}$ Louis Renner GmbH, 85232 Bergkirchen, Germany \\ E-mail: alexander.v.mueller@ipp.mpg.de
}

June 2019

\begin{abstract}
The exhaust of power and particles is currently considered as one of the ultimate challenges in view of the design of a power producing magnetic confinement thermonuclear fusion device, like DEMO. One predominantly challenging aspect in this regard is the design and manufacture of divertor target plasma-facing components (PFCs) that have to sustain substantial particle, heat and neutron fluxes during fusion operation. With respect to the design of highly loaded actively cooled PFCs, copper $(\mathrm{Cu})$ alloys are currently regarded as state-of-the-art structural heat sink materials. However, it has been underlined that the use of $\mathrm{Cu}$ alloys in PFCs implies issues mainly due to the behaviour of these materials under neutron irradiation characterised by a pronounced loss of ductility at lower and a loss of strength at elevated temperatures. These operating temperature limitations impose a strong constraint on the design of divertor PFCs and have regarding DEMO in the literature been termed a high impact design engineering risk. Against this background, the development of tungsten-copper (W-Cu) composites as potentially advanced heat sink materials for highly loaded PFCs was pursued by the authors during recent years. The progress of these developments is discussed in the present paper in terms of results of high-heat-flux tests conducted on PFC mock-ups that comprised W-Cu composite material heat sinks. Overall, the results of these tests indicate that $\mathrm{W}-\mathrm{Cu}$ composites can indeed be regarded a viable class of advanced materials for the heat sink of highly loaded PFCs.
\end{abstract}

Keywords: tungsten, copper, metal matrix composite, plasma-facing component, heat sink material

Submitted to: Phys. Scr. 


\section{Introduction}

The topic of power and particle exhaust is currently considered as one of the ultimate challenges in view of the design of a power producing magnetic confinement thermonuclear fusion device, like DEMO. One predominantly challenging aspect in this regard is the design and manufacture of divertor target plasma-facing components (PFCs) that have to sustain substantial particle, heat and neutron fluxes during fusion operation.

With respect to the design of highly loaded, actively cooled PFCs tungsten (W) is currently considered the preferred plasma-facing material (PFM) while copper $(\mathrm{Cu})$ alloys are regarded as preferred structural heat sink materials (HSMs). The current state-of-the-art divertor target PFC design that makes use of such materials and will be used within the ITER divertor is a so-called monoblock design where $\mathrm{W}$ armour tiles are joined to a water-cooled copper-chromium-zirconium $(\mathrm{CuCrZr})$ heat sink pipe with the help of a soft $\mathrm{Cu}$ interlayer [1].

This design has proven to fulfil the ITER divertor target qualification criteria [2, 3]. However, when such a design is directly applied to a DEMO environment issues arise mainly due to the fact that divertor PFCs in DEMO are foreseen to be in operation for 2 full power years meaning that they will be exposed to high fusion neutron doses leading to significant PFC material damage $[4,5]$.

The precipitation hardened $\mathrm{Cu}$ alloy $\mathrm{CuCrZr}$ is currently regarded as the most appropriate HSM for highly heat-loaded, water-cooled PFCs in present-day and future magnetic confinement fusion devices $[6,7,8,9$, 10]. However, it has been underlined that the use of $\mathrm{Cu}$ alloys, including $\mathrm{CuCrZr}$, in a DEMO environment implies issues. This is mainly due to the behaviour of $\mathrm{Cu}$ alloys under neutron irradiation characterised by a pronounced loss of ductility at lower and a loss of strength at elevated operating temperatures $[11,12,13,14]$. In the literature, a lower operating temperature limit of $180^{\circ} \mathrm{C}[12]$ as well as a maximum operating temperature of approximately $300^{\circ} \mathrm{C}[11]$ have been recommended for the use of $\mathrm{CuCrZr}$ in DEMO divertor PFCs.

The abovementioned operating temperature limitations impose a strong constraint on the design of divertor PFCs and have in the literature been termed a high impact design engineering risk regarding DEMO [12]. Apart from that, if within a divertor PFC design a $\mathrm{W}$ armour material is combined with a $\mathrm{Cu}$ alloy heat sink a further issue arises as the two materials exhibit inherently different thermomechanical properties, especially coefficients of thermal expansion (CTEs). This mismatch represents a driving force that inevitably leads to high thermal stresses in a PFC during cyclic HHF loading.

Against this background, tungsten-copper (W-Cu) composite materials are currently of interest as potentially advanced heat sink materials for highly loaded PFCs [15, 16, 17]. During recent years, the development of $\mathrm{W}-\mathrm{Cu}$ composites for $\mathrm{PFC}$ applications was pursued by the authors. The progress of these developments is discussed in the following in terms of results of high-heat-flux (HHF) tests conducted on PFC mock-ups that comprised W-Cu composite heat sinks. 


\section{Tungsten-copper composites}

W-Cu metal matrix composites (MMCs) can be regarded as suitable potentially advanced PFC heat sink materials due to the following reasons [16, 18, 19, 20, 21, 22]:

- W reinforcements in the $\mathrm{W}-\mathrm{Cu} \mathrm{MMC}$ enhance the strength properties of the material, especially at elevated temperatures.

- The $\mathrm{Cu}$ matrix leads to a high overall thermal conductivity of the MMC, as well as an acceptably ductile material behaviour for sufficiently high $\mathrm{Cu}$ contents.

- The W-Cu MMC material properties can - to some extent - be tailored by adjustment of the composite structure; this can for example be exploited by reducing the $\mathrm{CTE}$ mismatch with respect to $\mathrm{W}$ in order to minimise thermal stress levels at PFM to heat sink joints.

- The material system W-Cu is particularly suited for MMC fabrication by means of liquid infiltration of open porous $\mathrm{W}$ preforms due to the following reasons:

- The binary system $\mathrm{W}-\mathrm{Cu}$ does not show any interfacial reaction or mutual solubility.

- There is a distinct difference in the melting points of $\mathrm{Cu}\left(\mathrm{T}_{\mathrm{m}, \mathrm{Cu}}=1083^{\circ} \mathrm{C}\right)$ and $\mathrm{W}\left(\mathrm{T}_{\mathrm{m}, \mathrm{W}}=3400^{\circ} \mathrm{C}\right)$.

- The wettability of $\mathrm{W}$ with $\mathrm{Cu}$ melt is good.

- The basic constituent materials for W-Cu MMCs are readily and commercially available.

\section{Tungsten particle-reinforced copper}

One type of $\mathrm{W}-\mathrm{Cu}$ MMCs of interest with respect to PFC heat sink application are $W$ particle-reinforced $\mathrm{Cu}\left(\mathrm{W}_{\mathrm{p}}-\mathrm{Cu}\right)$ composites. Such MMCs are in principle known as it has long been recognised that these composite metals offer an interesting combination of material properties $[18,23] . \mathrm{W}_{\mathrm{p}}-\mathrm{Cu}$ composites can be fabricated by means of $\mathrm{Cu}$ melt infiltration of powder metallurgically produced open porous $\mathrm{W}$ compacts. Following such an approach, viable materials with compositions ranging from typically $60-40 \mathrm{wt} . \%$ to $90-10$ wt.\% W-Cu [21] - which corresponds to approximately 40-60vol.\% to 80-20vol.\% $\mathrm{W}-\mathrm{Cu}$ - can be fabricated. This composition range offers notable flexibility in terms of realisable macroscopic material properties. Nowadays, $\mathrm{W}_{\mathrm{p}}-\mathrm{Cu}$ MMCs are for example used as circuit breakers in high voltage applications due to their high thermal and electrical conductivity, their high-temperature stability as well as their high ablation resistance [22].

In Figure 1, a typical optical microsection of a $\mathrm{W}_{\mathrm{p}}-\mathrm{Cu}$ material with a nominal composition of 60-40wt.\% W-Cu (infiltrated matrix: Cu-OFE (oxygen-free electronic copper)) is illustrated. The microsection in Figure 1 illustrates the two different phases of the MMC which can clearly be distinguished. Furthermore, it can be seen that the material is fully infiltrated with the $\mathrm{Cu}$ matrix and that it does not show plainly 


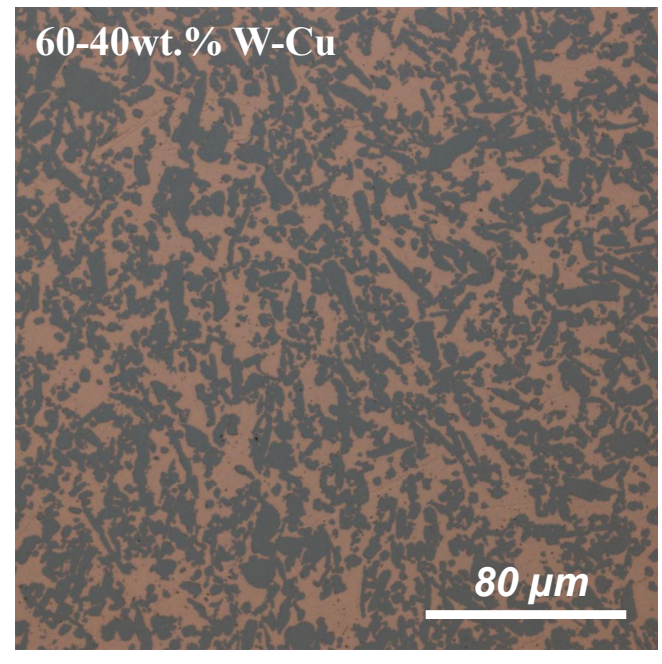

Figure 1. Typical optical microsection of a $\mathrm{W}_{\mathrm{p}}-\mathrm{Cu} \mathrm{MMC}$ (infiltrated matrix: $\mathrm{Cu}-$ OFE) with a nominal composition of $60-40 \mathrm{wt} \% \mathrm{~W}-\mathrm{Cu}$.

visible porosity which is an important prerequisite for acceptable thermophysical and -mechanical properties of the material in general. Further material characterisation results regarding the $\mathrm{W}_{\mathrm{p}}-\mathrm{Cu}$ MMCs investigated within recent years by the authors with respect to PFC application can e.g. be found in references [15, 24, 25].

An example for an application of a $\mathrm{W}_{\mathrm{p}}-\mathrm{Cu} \mathrm{MMC}$ to a $\mathrm{PFC}$ mock-up is illustrated in Figure 2, which shows a flat-tile type PFC mock-up with a $\mathrm{W}_{\mathrm{p}}-\mathrm{Cu}$ heat sink block with a composition of 70-30wt.\% W-Cu (infiltrated matrix: OFE-Cu). For the mock-up as

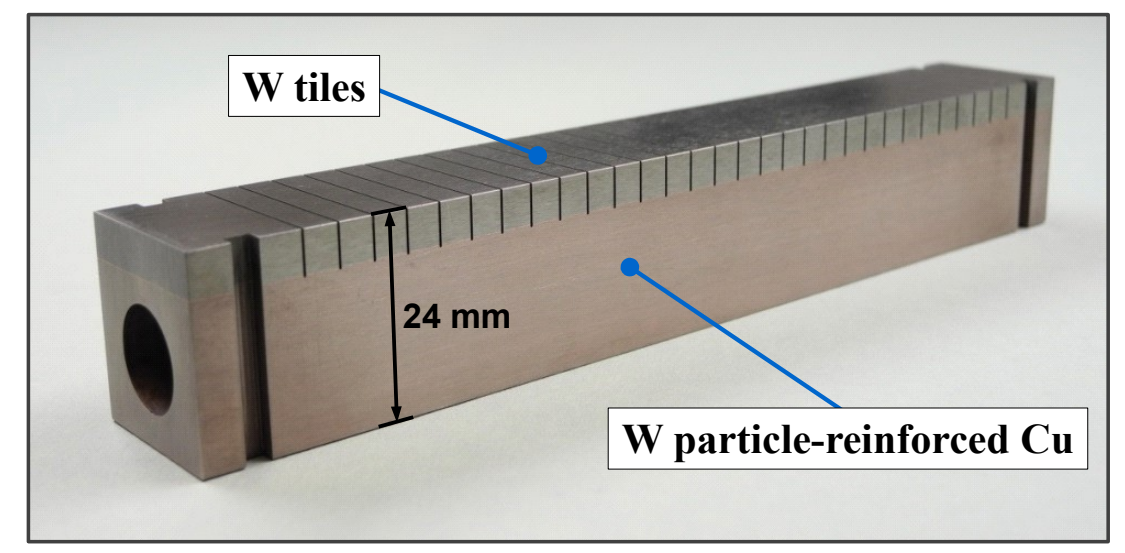

Figure 2. Flat-tile type PFC mock-up with $\mathrm{W}_{\mathrm{p}}-\mathrm{Cu}$ composite heat sink with a composition of 70-30wt.\% W-Cu (infiltrated matrix: OFE-Cu).

illustrated in Figure 2, the bonding of the W PFM tiles to the $\mathrm{W}_{\mathrm{p}}-\mathrm{Cu}$ heat sink was realised during the melt infiltration of the MMC heat sink within a one-temperature process. The manufacturing of the mock-up, which was performed in an industrial environment (Louis Renner GmbH, 85232 Bergkirchen, Germany), can accordingly be 
described as follows:

- The porous $\mathrm{W}$ compact for the $\mathrm{W}_{\mathrm{p}}-\mathrm{Cu}$ MMC heat sink block is assembled together with a $\mathrm{W}$ plate within a mould.

- The assembly is $\mathrm{Cu}$ infiltrated bonding the $\mathrm{W}$ PFM to the $\mathrm{W}_{\mathrm{p}}-\mathrm{Cu}$ MMC heat sink block.

- The joined assembly is machined to the desired dimensions, including the cooling channel as well as the castellation of the $\mathrm{W}$ plate.

In Figure 3, an optical microsection of a $\mathrm{W} / \mathrm{W}_{\mathrm{p}}-\mathrm{Cu}$ joint that has been produced with the melt infiltration procedure applied during mock-up fabrication is illustrated. It can be seen that the joint quality is sound demonstrating the viability of the applied joining procedure. Furthermore, it can be seen that a $\mathrm{Cu}$ layer with a thickness of approximately $10 \mu \mathrm{m}$ develops in between the materials during the melt infiltration/joining. The

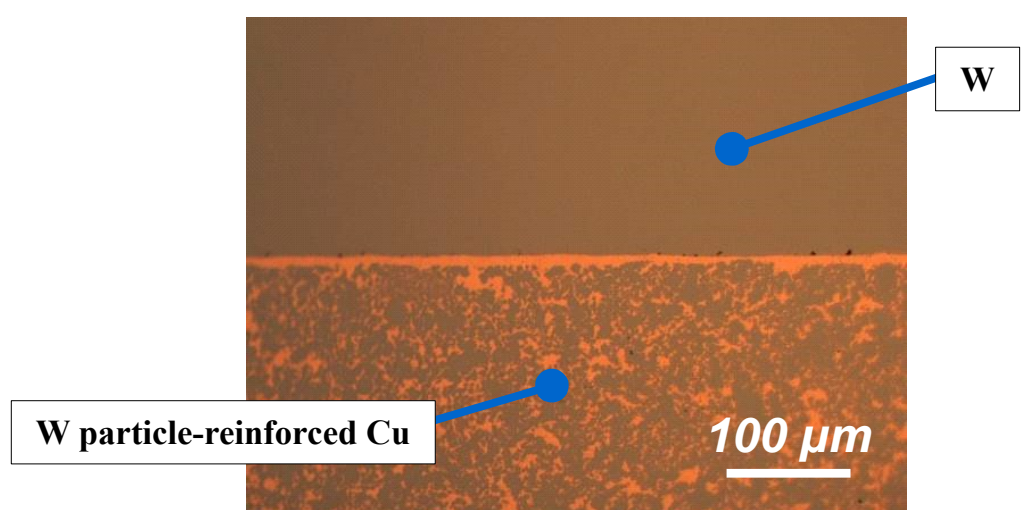

Figure 3. Optical microsection of a $\mathrm{W} / \mathrm{W}_{\mathrm{p}}-\mathrm{Cu}$ joint produced through bonding monolithic $\mathrm{W}$ to $\mathrm{W}_{\mathrm{p}}-\mathrm{Cu}$ during the $\mathrm{Cu}$ melt infiltration process of the MMC.

main expected beneficial effect of a PFC design as is illustrated in Figure 2 lies in a reduced CTE mismatch between the $\mathrm{W}$ PFM tiles and the $\mathrm{W}_{\mathrm{p}}-\mathrm{Cu}$ MMC heat sink. Ultimately, this mitigates the risk of cracking at or near the bonding interface as stress concentrations occurring at the free edges of the bond interface are relaxed. The issue with stress singularities at the interface of bonded dissimilar materials under mechanical and thermal loading is well-known and was investigated in [26, 27] and applied to joints of highly heat-loaded PFCs in [28].

The mock-up as illustrated in Figure 2 was HHF tested within the neutral beam facility GLADIS (Garching Large Divertor Sample Test Facility) [29] at IPP Garching with the following cold water cooling conditions:

- Coolant inlet temperature of $T_{i n}=20^{\circ} \mathrm{C}$,

- static coolant pressure of $p_{\text {static }}=10$ bar,

- coolant flow velocity of $v=12 \mathrm{~m} \mathrm{~s}^{-1}$ and

- use of a swirl tape insert with a twist ratio of 2 and a tape thickness of $0.8 \mathrm{~mm}$. 
HHF loading was applied as follows:

- HHF screening up to $22 \mathrm{MW} \mathrm{m}^{-2}$ as well as

- cyclic HHF loading up to 370 cycles at $20 \mathrm{MW} \mathrm{m}^{-2}$.

During the HHF tests reported on in the present paper applied heat pulses had a duration of $10 \mathrm{~s}$ and the dwell times in between heat pulses were $90 \mathrm{~s}$. The main results of the HHF testing can be summarised as follows: The mock-up exhibited a stable behaviour during screening up to $22 \mathrm{MW} \mathrm{m}^{-2}$ without the development of hot spots that would indicate hampering material or joint defects. This indicated a good manufacturing quality of the $\mathrm{W}_{\mathrm{p}}-\mathrm{Cu} \mathrm{MMC}$ as well as the $\mathrm{W} / \mathrm{W}_{\mathrm{p}}-\mathrm{Cu}$ joint. During the cyclic loading with $20 \mathrm{MW} \mathrm{m}^{-2}$ no deterioration of HHF performance was detected up to 300 pulses, which corresponds to the stationary load design cycle number for the ITER divertor target at $20 \mathrm{MW} \mathrm{m}^{-2}[1,6]$. Further cyclic loading of the mock-up lead to the development of bonding defects at the $\mathrm{W} / \mathrm{W}_{\mathrm{p}}-\mathrm{Cu}$ joint. The experiment was continued up to 370 load cycles at $20 \mathrm{MW} \mathrm{m}^{-2}$, when $\mathrm{W}$ tile overheating due to detachment was unambiguously visible. In Figure 4, infrared (IR) images of the mock-up during the HHF loading for pulse numbers 1, 300 and 370 are illustrated. It can be seen that the

(a) $1^{\text {st }}$ pulse

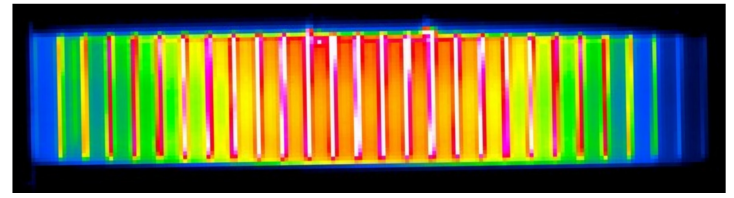

(b) $300^{\text {th }}$ pulse

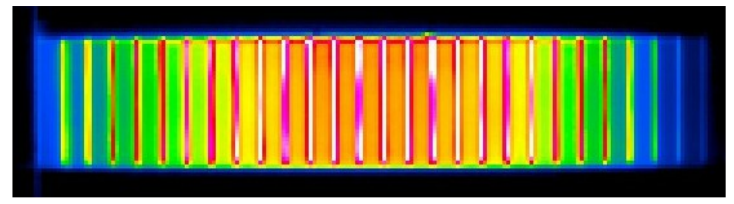

(c) $370^{\text {th }}$ pulse

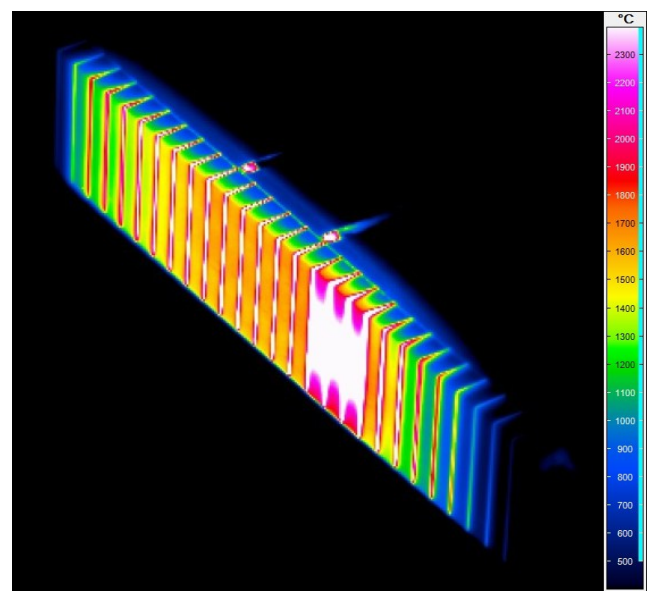

Figure 4. IR images of flat-tile type PFC mock-up with $\mathrm{W}_{\mathrm{p}}-\mathrm{Cu}$ MMC heat sink during HHF loading with $20 \mathrm{MW} \mathrm{m}^{-2}$ for pulse numbers 1,300 and 370 . 
temperature distributions are homogeneous and qualitatively similar for pulse numbers 1 and 300, but that there are hot spots, i.e. overheating $W$ tiles, visible during pulse number 370. In Figure 5, post HHF test images of the mock-up after 370 applied load cycles at $20 \mathrm{MW} \mathrm{m}^{-2}$ are shown. In Figure 5a, the centred top view on the heat-loaded $\mathrm{W}$ tiles of the mock-up is shown. No significant material degradation or macroscopic cracking can be seen. In Figure 5b, a side view on the partially detached $\mathrm{W}$ armour tiles and the $\mathrm{W} / \mathrm{W}_{\mathrm{p}}-\mathrm{Cu}$ bond interfaces is illustrated. The magnified image shows the $\mathrm{W}$ tile debonding that developed during the cyclic HHF loading. Especially, it can be seen that melting of the $\mathrm{Cu}$ layer occured at the bond interface due to tile overheating. Regarding
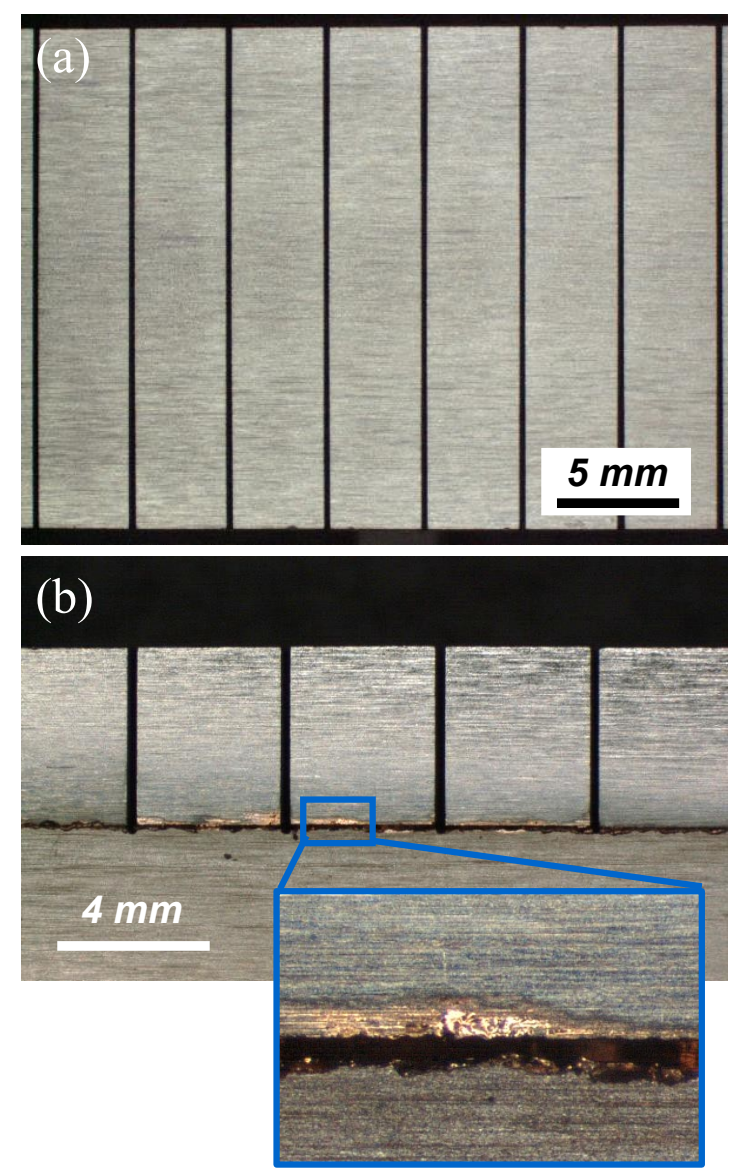

Figure 5. Flat-tile type PFC mock-up with $\mathrm{W}_{\mathrm{p}}-\mathrm{Cu} \mathrm{MMC}$ heat sink after 370 applied HHF load cycles at $20 \mathrm{MW} \mathrm{m}^{-2}$ : (a) Centred top view on HHF loaded W tiles and (b) side view on defective $\mathrm{W} / \mathrm{W}_{\mathrm{p}}-\mathrm{Cu}$ bond interfaces.

the flat-tile design as described above, high temperatures occuring at the $\mathrm{W} / \mathrm{W}_{\mathrm{p}}-\mathrm{Cu}$ bond interfaces are considered as main performance-limiting factor. Thermal finite element analysis (FEA) indicates that at the edges of the bond interfaces temperatures of more than $700{ }^{\circ} \mathrm{C}$ occur at a heat load of $20 \mathrm{MW} \mathrm{m}^{-2}$ as is illustrated in Figure 6 . It seems that at such temperatures, the $\mathrm{W} / \mathrm{W}_{\mathrm{p}}-\mathrm{Cu}$ bond interface, which essentially is a thin $\mathrm{Cu}$ layer (cf. Figure 3), suffers from fatigue damage and can hence not withstand 
the cyclic HHF loading.
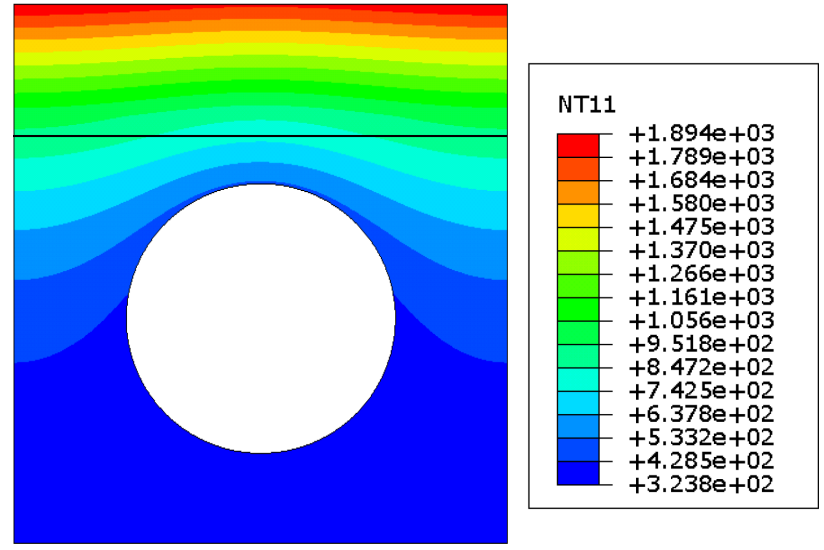

Figure 6. Temperature distribution according to thermal FEA of flat-tile type PFC design with $\mathrm{W}_{\mathrm{p}}-\mathrm{Cu} \mathrm{MMC}$ heat sink as illustrated in Figure 2 at a heat load of $20 \mathrm{MW} \mathrm{m}^{-2}$ (temperature scale in $\mathrm{K}$ ).

\section{Tungsten fibre-reinforced copper}

Another class of $\mathrm{W}-\mathrm{Cu}$ MMCs of interest with regard to PFC heat sink application are $W$ fibre-reinforced $\mathrm{Cu}\left(\mathrm{W}_{\mathrm{f}}-\mathrm{Cu}\right)$ composites. In principle, $\mathrm{W}_{\mathrm{f}}-\mathrm{Cu}$ MMCs are of specific interest due to the well-known eligibility of fibrous reinforcements in composites [30]. The preferred reinforcing fibres for the $\mathrm{W}_{\mathrm{f}} \mathrm{Cu}$ MMCs are commercially available drawn potassium $(\mathrm{K})$ doped $\mathrm{W}$ fibres, which exhibit very beneficial properties, namely a high tensile strength as well as a ductile failure behaviour even after annealing at high temperature [31].

The fabrication of the $\mathrm{W}_{\mathrm{f}^{-}} \mathrm{Cu}$ MMCs investigated within the present work comprises the application of techniques known from textile technology for fibrous preform production [32] as well as liquid $\mathrm{Cu}$ infiltration processing. In this context, the authors have worked during recent years on the optimisation of the fabrication of $\mathrm{W}_{\mathrm{f}}-\mathrm{Cu}$ material in pipe configuration for application to actively water cooled PFCs [15, 17].

Such $\mathrm{W}_{\mathrm{f}} \mathrm{Cu}$ MMCs in pipe configuration were applied to monoblock type PFC mockups. In Figure 7, such a mock-up, which comprises $4 \mathrm{~W}$ armour monoblocks with a thickness of $12 \mathrm{~mm}$, is shown after fabrication. The following materials were used for its manufacturing:

- W monoblocks with $\mathrm{Cu}$ interlayer (interlayer thickness: $1 \mathrm{~mm}$; supplier: AT\&M Co., Ltd, China),

- $\mathrm{W}_{\mathrm{f}} \mathrm{Cu}$ pipe (inner diameter: $12 \mathrm{~mm}$, wall thickness: $1.5 \mathrm{~mm}$ ),

- Brazing alloy foil with 80wt.\% Au, 20wt.\% Cu (supplier: LOT-TEK GmbH, Germany). 




Figure 7. Monoblock type PFC mock-up with $\mathrm{W}_{\mathrm{f}-\mathrm{Cu}} \mathrm{MMC}$ heat sink pipe before HHF loading.

The mock-up was joined through brazing the $\mathrm{W}$ monoblocks at the $\mathrm{Cu}$ interlayer to the $\mathrm{W}_{\mathrm{f}} \mathrm{Cu}$ pipe and subsequently loaded within the HHF test facility GLADIS. The following loading was applied initially with cold water cooling conditions as described above:

- HHF screening up to $25 \mathrm{MW} \mathrm{m}^{-2}$ as well as

- cyclic HHF loading up to 100 cycles at $10 \mathrm{MW} \mathrm{m}^{-2}$.

After that, the mock-up was tested with the following DEMO relevant hot water cooling conditions:

- Coolant inlet temperature of $T_{i n}=130^{\circ} \mathrm{C}$,

- coolant inlet pressure of $p_{\text {in }}=40 \mathrm{bar}$,

- coolant flow velocity of $v=16 \mathrm{~m} \mathrm{~s}^{-1}$ and

- use of a swirl tape insert with a twist ratio of 2 and a tape thickness of $0.8 \mathrm{~mm}$.

HHF loading was then applied as follows:

- HHF screening up to $20 \mathrm{MW} \mathrm{m}^{-2}$ as well as

- cyclic HHF loading up to 1000 cycles at $20 \mathrm{MW} \mathrm{m}^{-2}$.

In Figure 8, IR and optical images of the mock-up during the cyclic HHF loading with $20 \mathrm{MW} \mathrm{m}^{-2}$ and hot water cooling conditions for pulse numbers 1, 100, 500 and 1000 are shown. It can be seen that the mock-up exhibits a stable behaviour under HHF loading throughout the accumulating pulses without the development of hot spots that would indicate hampering material or joint defects. Furthermore, Figure 8 indicates two more findings. The IR images suggest that strong surface modifications occur during the accumulating heat pulses as is indicated by the seemingly higher temperatures of the loaded W monoblock surfaces for high pulse numbers. However, this is rather attributed to a change in emissivity of the modified W surfaces than due to a real increase of the surface temperatures. Apart from that, it can be seen that the W monoblocks underwent accumulated plastic deformation. The monoblock surfaces do after 1000 heat pulses not exhibit a shape as rectangular as can be seen within the images for heat pulse number 1. In Figure 9, images of the mock-up illustrated in Figures 7 and 8 after HHF testing are shown. These images confirm that the cyclic heat loading induced strong surface 


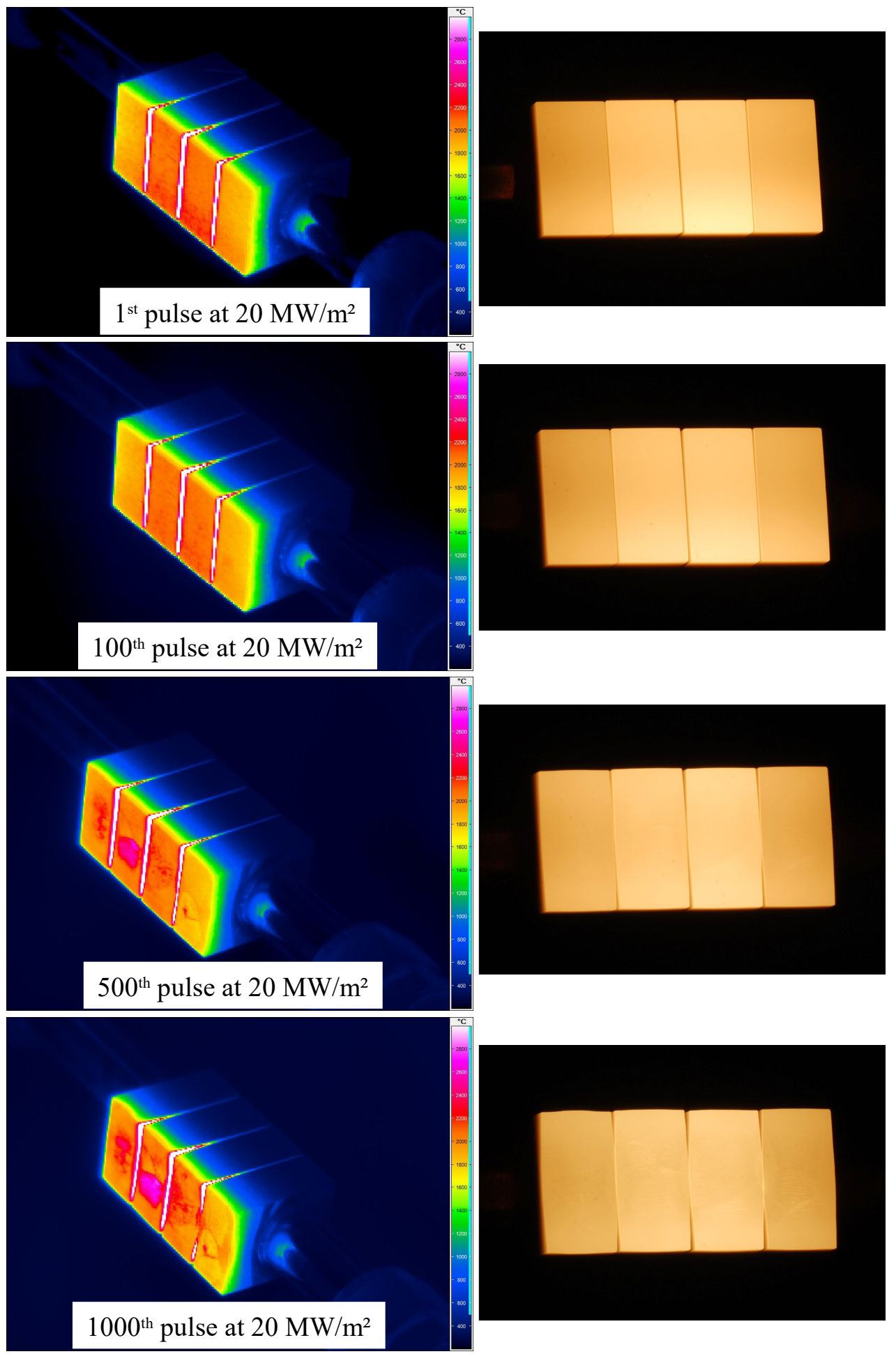

Figure 8. IR and optical images of monoblock type PFC mock-up with $\mathrm{W}_{\mathrm{f}}-\mathrm{Cu} \mathrm{MMC}$ heat sink pipe during HHF loading with $20 \mathrm{MW} \mathrm{m}^{-2}$ for pulse numbers $1,100,500$ and 1000 . 

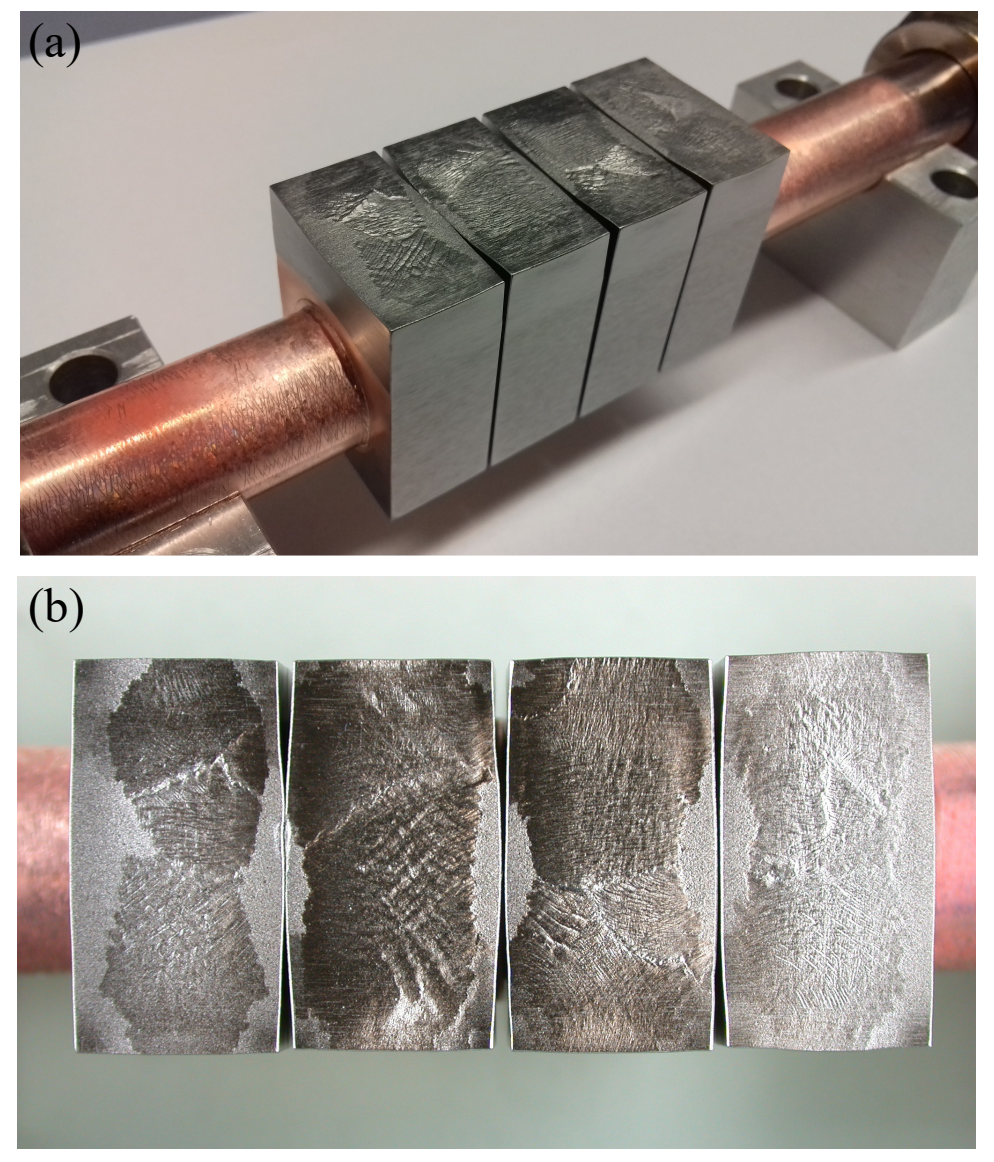

Figure 9. Monoblock type PFC mock-up with $\mathrm{W}_{\mathrm{f}}-\mathrm{Cu} \mathrm{MMC}$ heat sink pipe after 1000 HHF pulses at $20 \mathrm{MW} \mathrm{m}^{-2}$ with hot water cooling conditions: (a) Oblique specimen view and (b) top view on heat-loaded surface.

modifications on as well as plastic deformation of the $\mathrm{W}$ monoblocks. Nevertheless, it can be seen that the mock-up and especially the $\mathrm{W}_{\mathrm{f}}-\mathrm{Cu}$ heat sink pipe are well intact. In Figure 10, an axial metallographic cross section of one half (two W monoblocks) of the HHF loaded mock-up illustrated in Figure 9 is shown. In the magnified image, the heat-loaded side of one monoblock is shown. In general, it can be seen that the $\mathrm{W}_{\mathrm{f}}-\mathrm{Cu}$ MMC pipe is well intact without significant plastic deformation or plainly visible crack or debonding defects. Apart from that, it can be seen that plastic deformation not only of the $\mathrm{W}$ monoblock but also of the joint including the $\mathrm{Cu}$ interlayer has occured, especially at the edges. Furthermore, some porosity can be identified within the braze layer though it is not clear if these joint defects were present from the beginning or if and how they evolved during the cyclic HHF loading. 


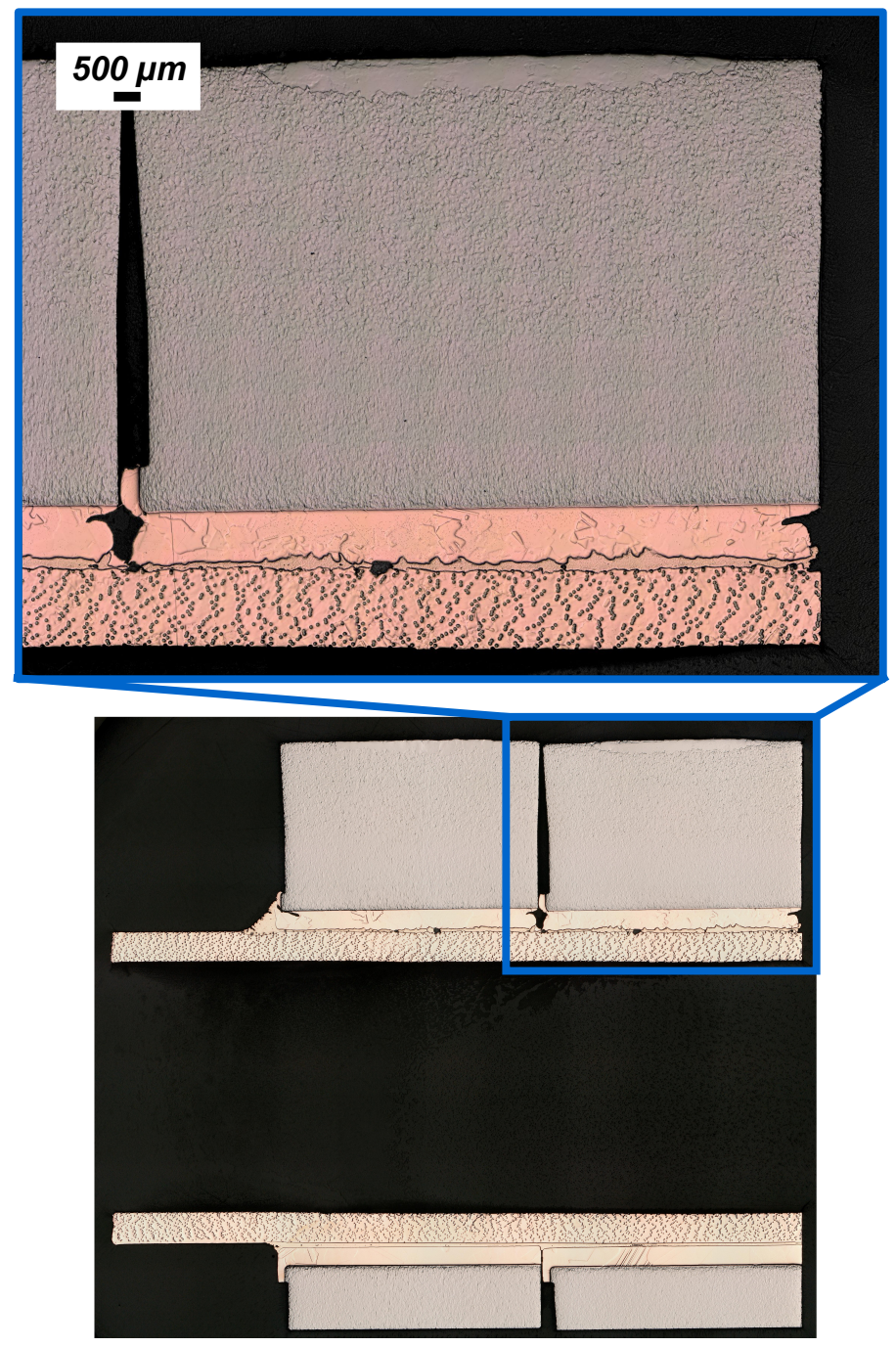

Figure 10. Metallographic cross section of monoblock type PFC mock-up with $\mathrm{W}_{\mathrm{f}^{-}}$ $\mathrm{Cu} \mathrm{MMC}$ heat sink pipe after $1000 \mathrm{HHF}$ pulses at $20 \mathrm{MW} \mathrm{m}^{-2}$ with hot water cooling conditions.

\section{Conclusions}

The present paper discusses W-Cu MMCs as potentially advanced materials for the heat sink of highly loaded PFCs of future magnetic confinement thermonuclear fusion devices, like DEMO. The suitability of such materials was in this regard mainly assessed based on results of HHF tests on PFC mock-ups that comprised W-Cu MMC heat sinks. In more detail, two different types of $\mathrm{W}-\mathrm{Cu}$ MMCs were discussed: $\mathrm{W}_{\mathrm{p}}-\mathrm{Cu}$, which was applied within a $\mathrm{W}$ flat-tile type PFC mock-up as well as $\mathrm{W}_{\mathrm{f}} \mathrm{Cu}$, which was applied within a W monoblock type PFC mock-up. Regarding the former, it was found that the overall HHF performance of the mock-up was good but eventually limited due to typical flat-tile design issues inducing failure of the $\mathrm{W} / \mathrm{W}_{\mathrm{p}}-\mathrm{Cu}$ bonding interface during cyclic heat loading at $20 \mathrm{MW} \mathrm{m}^{-2}$. Regarding the latter, a very stable HHF performance was 
found during cyclic heat loading up to 1000 pulses at $20 \mathrm{MW} \mathrm{m}^{-2}$ without notable HHF performance degradation. These results lead to the following main conclusions:

- W-Cu MMCs can be fabricated by means of liquid $\mathrm{Cu}$ melt infiltration techniques with good material quality, i.e. with material properties acceptable for HHF applications.

- W-Cu MMCs can be fabricated in a reasonable shape with respect to PFC heat sink applications.

- The reliable joining of W-Cu MMCs with W armour tiles can be realised, although it has to be investigated in more detail if the joining technologies proposed within the present work are applicable to divertor PFCs of future fusion devices, like DEMO.

- During the HHF tests reported on herein no failure of the W-Cu MMC materials itself was observed, which ultimately confirms the potential suitability of such materials for PFC applications.

To summarise, it can be stated that W-Cu MMCs can indeed be regarded a viable class of advanced materials for the heat sink of highly loaded PFCs. However, several aspects have to be investigated in the future in order to forge ahead with these developments. In this regard, the following two are considered as most important: The effects of fusion neutron irradiation on the W-Cu MMCs have to be investigated. Apart from that, the optimisation and upscaling of industrially viable material fabrication have to be assessed practically.

\section{Acknowledgement}

This work has been carried out within the framework of the EUROfusion Consortium and has received funding from the Euratom research and training programme 2014-2018 and 2019-2020 under grant agreement No 633053. The views and opinions expressed herein do not necessarily reflect those of the European Commission.

\section{References}

[1] R.A. Pitts et al. Physics conclusions in support of ITER W divertor monoblock shaping. Nuclear Materials and Energy, 12:60-74, 2017.

[2] P. Gavila et al. High heat flux testing of EU tungsten monoblock mock-ups for the ITER divertor. Fusion Engineering and Design, 98-99:1305-1309, 2015.

[3] G. Pintsuk et al. Characterization of ITER tungsten qualification mock-ups exposed to high cyclic thermal loads. Fusion Engineering and Design, 98-99:1384-1388, 2015.

[4] G. Federici et al. Overview of EU DEMO design and R\&D activities. Fusion Engineering and Design, 89(7):882-889, 2014.

[5] G. Federici et al. European DEMO design strategy and consequences for materials. Nuclear Fusion, 57(9):092002, 2017.

[6] T. Hirai et al. Use of tungsten material for the ITER divertor. Nuclear Materials and Energy, 9:616-622, 2016.

[7] J.H. You et al. Conceptual design studies for the European DEMO divertor: Rationale and first results. Fusion Engineering and Design, 109-111:1598-1603, 2016. 
[8] J. Boscary et al. Design improvement of the target elements of Wendelstein 7-X divertor. Fusion Engineering and Design, 87(7):1453-1456, 2012.

[9] M. Matsukawa et al. Status of JT-60SA tokamak under the EU-JA Broader Approach Agreement. Fusion Engineering and Design, 83(7):795-803, 2008.

[10] M. Missirlian et al. The WEST project: Current status of the ITER-like tungsten divertor. Fusion Engineering and Design, 89(7):1048-1053, 2014.

[11] S.J. Zinkle. Applicability of copper alloys for DEMO high heat flux components. Physica Scripta, 2016(T167):014004, 2016.

[12] D. Stork et al. Developing structural, high-heat flux and plasma facing materials for a near-term DEMO fusion power plant: The EU assessment. Journal of Nuclear Materials, 455(1-3):277-291, 2014.

[13] M. Li and S.J. Zinkle. Physical and Mechanical Properties of Copper and Copper Alloys. Comprehensive Nuclear Materials, 4:667-690, 2012. ISBN 978-0-08-056033-5.

[14] S.A. Fabritsiev et al. Neutron spectrum and transmutation effects on the radiation damage of copper alloys. Fusion Engineering and Design, 36(4):505-513, 1997.

[15] A. v. Müller et al. Melt infiltrated tungsten-copper composites as advanced heat sink materials for plasma facing components of future nuclear fusion devices. Fusion Engineering and Design, 124:455-459, 2017.

[16] J.H. You. Copper matrix composites as heat sink materials for water-cooled divertor target. Nuclear Materials and Energy, 5:7-18, 2015.

[17] J.H. You et al. European divertor target concepts for DEMO: Design rationales and high heat flux performance. Nuclear Materials and Energy, 16:1-11, 2018.

[18] R. Kieffer and W. Hotop. Pulvermetallurgie und Sinterwerkstoffe (English translation: Powder Metallurgy and Sintered Materials). Springer, 1948. ISBN 978-3-540-01339-6.

[19] C.J. Smithells. Metals Reference Book. Butterworths, 5th edition, 1976. ISBN 0408706279.

[20] D.L. McDanels. Tungsten Fiber Reinforced Copper Matrix Composites: A review. NASA Technical Paper 2924, 1989.

[21] E. Lassner and W.-D. Schubert. Tungsten: Properties, Chemistry, Technology of the Element, Alloys, and Chemical Compounds. Springer, 1999. ISBN 978-1-4613-7225-7.

[22] W. Schatt, K.-P. Wieters and B. Kieback. Pulvermetallurgie - Technologien und Werkstoffe (English translation: Powder Metallurgy - Technologies and Materials). Springer, 2nd edition, 2007. ISBN 978-3-540-23652-8.

[23] R. Imm and G. Stempel. Der Einfluß der Porosität auf einige Eigenschaften von Wolfram/KupferKontaktwerkstoffen (English translation: The Influence of Porosity on a Few Properties of Tungsten/Copper Contact Materials). Materialwissenschaft und Werkstofftechnik, 7(10):376$380,1976$.

[24] E. Tejado et al. The thermo-mechanical behaviour of W-Cu metal matrix composites for fusion heat sink applications: The influence of the Cu content. Journal of Nuclear Materials, 498:468$475,2018$.

[25] E. Tejado et al. Evolution of mechanical performance with temperature of $\mathrm{W} / \mathrm{Cu}$ and $\mathrm{W} / \mathrm{CuCrZr}$ composites for fusion heat sink applications. Materials Science and Engineering: A, 712:738$746,2018$.

[26] D. Munz and Y.Y. Yang. Stress Singularities at the Interface in Bonded Dissimilar Materials Under Mechanical and Thermal Loading. Journal of Applied Mechanics, 59:857-861, 1992.

[27] D. Munz and Y.Y. Yang. Stresses near the free edge of the interface in ceramic-to-metal joints. Journal of the European Ceramic Society, 13(5):453-460, 1994.

[28] J.H. You and H. Bolt. Analysis of singular interface stresses in dissimilar material joints for plasma facing components. Journal of Nuclear Materials, 299(1):1-8, 2001.

[29] H. Greuner et al. High heat flux facility GLADIS:: Operational characteristics and results of W7-X pre-series target tests. Journal of Nuclear Materials, 367-370:1444-1448, 2007.

[30] K.K. Chawla. Composite Materials: Science and Engineering. Springer, 3rd edition, 2013. ISBN 
978-0-387-74364-6.

[31] J. Riesch et al. Chemically deposited tungsten fibre-reinforced tungsten - The way to a mock-up for divertor applications. Nuclear Materials and Energy, 9:75-83, 2016.

[32] H. Gietl et al. Textile preforms for tungsten fibre-reinforced composites. Journal of Composite Materials, 0(0):0021998318771149, 2018. 